\title{
Learning Paradigms in e-Society
}

\author{
Gabriel ZAMFIR \\ Department of Economic Informatics and Cybernetics, \\ Academy of Economic Studies, Bucharest, Romania, \\ zamfir@ase.ro
}

Learning, defined both as the cognitive process of acquiring knowledge, and as the knowledge received by instruction, depends on the environment. Our world, analyzed as an educational environment, evolved from a natural native stage to a scientific technological based phase. Educative system, developed as a public service, including formal, non-formal and informal education, originated its foundations on the textbook, and at present, teacher preparation is based on the same technique. This article is designed as a conceptual basis analyze of learning in a scientific environment, in order to synthesize the interdependencies between the cognitive process of acquiring knowledge and the methods applied in knowledge conversion.

Keywords: Scientific Research, Higher Education, Learning Infrastructure, Deskwork, Fieldwork

1 Introduction

Scientific research is the methodological investigation of a scientific subject of a particular domain for the purpose of adding to knowledge. Learning can be analyzed as the specific process of knowledge growth. Scientific research results are saved in technology while individual learning is integrated in experience. The scientific progress is based on the equilibrium between experience and technology. This is why we can define the paradigm of learning as a function of technology applied in scientific research. In [1], the author reviews Thomas Kuhn's The Structure of Scientific Revolutions, and highlights the two different senses of "paradigm": exemplar and disciplinary matrix. The first sense is used to refer to the particular, concrete achievement that defines by example the course of all subsequent research in a scientific discipline while the second one is an entire theoretical, methodological, and evaluative framework within which scientists conduct their research. In [2], another author reviews the two key ideas of The Structure of Scientific Revolutions, the pattern of scientific change and the paradigms, which together can be thought of as analogous to a scientific theory: the first identifies and describes a pattern, and the second provides an explanation for the pattern. Another author
[3] analyses the basic concepts of the Kuhn's work: normal scientific research, which is conducted under a paradigm, or disciplinary matrix and revolutionary science, as the process by which one paradigm is replaced by another. The author lists the four elements of a disciplinary matrix: symbolic generalizations, metaphysical presumptions, values, and exemplars; then he assumes that a model is a kind of symbolic generalization, and that the goals of research come under the heading of 'values'. In his approach, normal science is about the construction of new models or the improvement of old ones, whereas paradigm change or revolutionary science is about theory change. At the time of publication, Kuhn introduced the new and controversial idea that scientists do not see anomalies, or even crises, as testing the paradigm itself. The same author mentions that for Kuhn, '...science students accept theories on the authority of teacher and text, not because of evidence'.

The three references related above reflects, first, the existence of a meta-language and of an object language in scientific research activities, and the possibility to use the same term in the group of the working terms and in the group of the scientific field's group, and second, the double function for the working terms: the descriptive one and the explanato- 
ry one. The first characteristic lead to the situation of creating or explaining a paradox, while the second characteristic lead to the possibility of creating a pedagogical environment in order to know, to understand and to apply. Technological innovation in a digital environment depends on the pattern of educational change in the pedagogical environment, while this is an application of a technological infrastructure. At the same time, this approach is developed as a methodological one, reconsidering the two sequential levels: theory and practice as two conceptual interdependent components, structured in a desktop-fieldwork paradigm, see the image presented in Fig. 1.

The main aim of the foundations of research is to adopt and update an appropriate terminology of research as a basic vocabulary of generic research for students and specialists in order to choose the correct theories, concepts or methods to use in their work [4]. The same author highlights the necessity of knowing and understanding the standard terms and concepts of the domain researched as soon as the most common way to begin a substantial piece of research is by undertaking a literature review which enables the researcher to around a general topic.

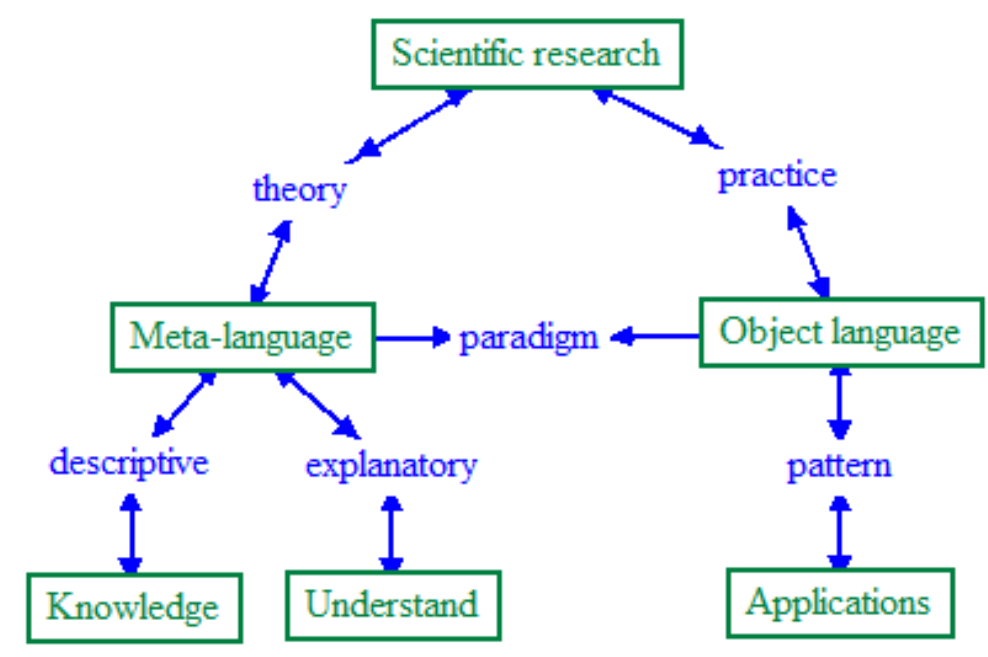

Fig. 1. Methodological approach based on concepts map

In [5] it was found that the character of human reasoning was not the same during various stages of development of human cognitive competencies. In the history of development of any field of scientific knowledge we can observe a number of stages: a prescientific period, a proto-scientific period and the scientific period. The first stage is associated with the three main sources of knowledge: experience, technology, and manuals for this, written in the native language of technology or translations. The second stage is characterized by the appearance of specialized word which signifies the appearance of the special notions and special professional activities. The third stage of cognition is characterized by scientific think- ing, which is based on the use of scientific theories and systems of concepts.

\section{Conceptual Framework}

The dynamic of the technological innovation generates two levels of implications regarding terminology: from the point of view of working terms (deskwork), the cluster of the innovation, and from the point of view of the scientific field (fieldwork), its label for knowing, understanding and using it. In [6], the authors analyzed the first perspective and concluded that the inconsistencies in labeling and operationalizing innovations in the new product literature may have contributed to the slow progression of knowledge in these areas. For example, [7, pp. 62-66] consider two alternative research dichotomies: qualita- 
tive/quantitative and deskwork/fieldwork. The first of this distinctions has been the subject of much debate. The second distinction is much more pragmatic, and hence less debated, and has to do with the individual researcher's preferences and opportunities for going out to do their research (fieldwork) or staying in the office, library or laboratory (deskwork).So, according with [7] the two concepts are based on type of activities, while in this paper, the two concepts are based on two class of terminologies (metalanguage and object language). According to their approach, [7] analyze that the distinction between fieldwork and deskwork is, obviously, also not clear-cut. It is debatable, for example, into which category one would place telephone or email interviews, which can be conducted at the desk but effectively take the researcher, at least electronically, into the field. The authors consider to be difficult to categorize the situation of using laptop in the field collecting data; they conclude that the development of information and communication technologies, in particular the growth of the Internet, is undoubtedly, blurring the fieldwork-deskwork distinction, in their acceptation. The same difficulties persists in the third digital edition of the book published in 2006.

As soon as the main result of the dynamic of the technological infrastructure is the esociety, focusing on this concept, we conclude that there are various definitions and approaches connected with it; one example if offered by [8]; the author considers that the e-society is the result of our new ability to compress almost infinitely both time and space; today, this allows the transmission of practically unlimited amounts of data, in real time, anywhere in the world. Another group of authors [9] review the concept and present e-society as a kind of society which steps toward improving people's lives, and also increasing people's awareness of the process of citizenship and city facilities. It is after making the services for the citizens one-phase and electronic. The most important goal of the e-society is to provide acceptable services for the citizens and to gain their satisfaction. The authors consider that continuing life in an informational society and e-cities requires special attention to the education of information and communication technology for the citizens. On the way to prepare the ecitizen, some solutions are presented and they are structured in computer skills, using the facilities of the e-city and culture building. In [10], the purpose of the paper is to engage with the debate on social exclusion in the e-society from the human development perspective, which goes beyond inequality in distribution of technological goods and services to emphasize the options, choice and opportunities related to assessing and using information.

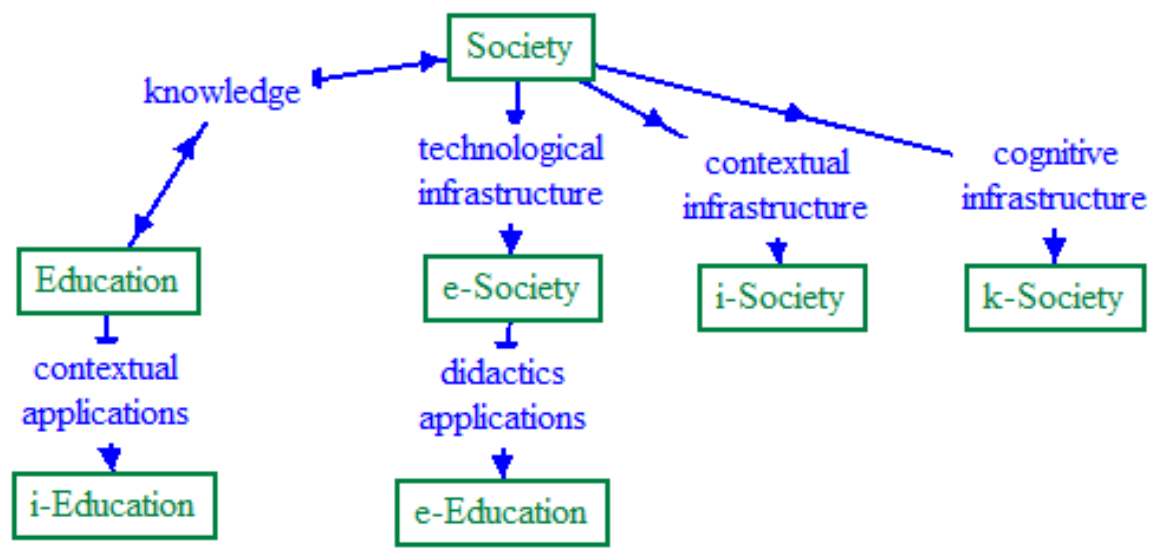

Fig. 2. Learning in e-Society: a lexical paradigm 
mation and communications technologies in our society, which integrates updated technological infrastructure. At this level of approach we identify an initial type of reasoning that can be called the naïve type, which uses common words and word-combinations and testifies that it was based on worldly wisdom and common-sense and operates with general notions, see the image presented in Fig. 2.

Technological infrastructure is a dynamic system which generates new borders for knowledge domain, for the whole society, revealing the e-society; e-education, the engine of the e-society, implies more complex activities, and, in this context, a key activity is represented by the scientific research in eeducation, correlated with a new functionality designed to turn the theory into practice. As soon as knowledge developed by scientific research in e-Education is recorded in technology, from a social perspective, the difficulties lies precisely to teach the knowledge workers in order to understand and apply available technology, and as a key of this demand, to train the trainers in a dynamic technological infrastructure [11]. As a result of this paradigm [12], the traditional Classroom, existing in education, could be completed and developed as an e-Class, supported by e-Learning, or as an e-Classroom, mediated by teacher assisted learning, see Fig. 3.

In this second stage, the meaning of some special notions could be explained by the specialists belonging to a certain profession. For example, e-Learning as the support for eClass has to be connected with the developers of e-Learning. This context generates other paradigms such as: information gap or digital divide. The complexity of the relation between language and knowledge introduced the necessity to recognize the triple nature of the concept in terminology: as a unit of knowledge, cognition, and thought [5]. We can find an educational example, published as a teacher's guide, in [13, pp.393-398], where e-learning is defining as a method (a $19^{\text {th }}$ one) for developing the active spirit. The author refers to an extended acceptation of the concept e-learning as: assisted/mediated computer instruction, digital/mobile education, multimedia instruction, online education, distance education, web education; at the same time, the same author presents, in a narrow sense, e-learning as a type of distance education or in a classroom, designed as a planned experience for teaching-learningevaluation, and mediated by the new information and communication technologies. Internet is define as a very active and interactive environment, and m-learning represents a method for learning anywhere and anytime. A similar content could be found at http://en.wikipedia.org/wiki/E-learning when searching for e-education, using Google.

Once the e-society is developed based on the technological infrastructure, the most important component of it become the escience. Reviewing the literature in this domain, we find a diversity approach regarding the concepts science or e-science. According to [14], e-science represents computationally intensive science carried out in highly distributed network environments. Most of the e-science research activities are focused on the development of tools to support scientific discovery. The author highlights the escience application concept as a scientific experiment built as a computer simulation. Escience applications are composed from various components including software and data. The UK National e-Science Centre (http://www.nesc.ac.uk/nesc/define.html) defines e-science as "the large scale science that will increasingly be carried out through distributed global collaborations enabled by the Internet. Typically, a feature of such collaborative scientific enterprises is that they will require access to very large data collections, very large-scale computing resources and high-performance visualization back to the individual user scientists". Analyzing the evolution of the science paradigms, [15] presents four stages: the empirical one, when science described natural phenomena, thousand year ago, the theoretical one, using models and generalizations, last few hundred years, the computational one, for simulating complex phenomena last few decades, and 
data exploration (e-science) stage, today where are developed unify theory, experiment, and simulation. The word e-science could be retrieved in eight references of this book but none in the content. Another example defining the science concept is the chapter Evolution and the Nature of Science, which can be found at the address (http://www.nap.edu/openbook.php?record_i $\mathrm{d}=5787$ \&page $=27$ ) of The National Academies Press, where is mentioned that science is a particular way of knowing about the world. In science, explanations are restricted to those that can be inferred from confirmable data - the results obtained through obser- vations and experiments that can be substantiated by other scientists. Anything that can be observed or measured is amenable to scientific investigation. Explanations that cannot be based on empirical evidence are not a part of science. In the chapter Evolution and the National Science Education Standards, the same publication highlights that the science education program standards discuss the planning and actions needed to translate the Standards into programs that reflect local contexts and policies. And the science education system standards consist of criteria for judging the performance of the overall science education system.

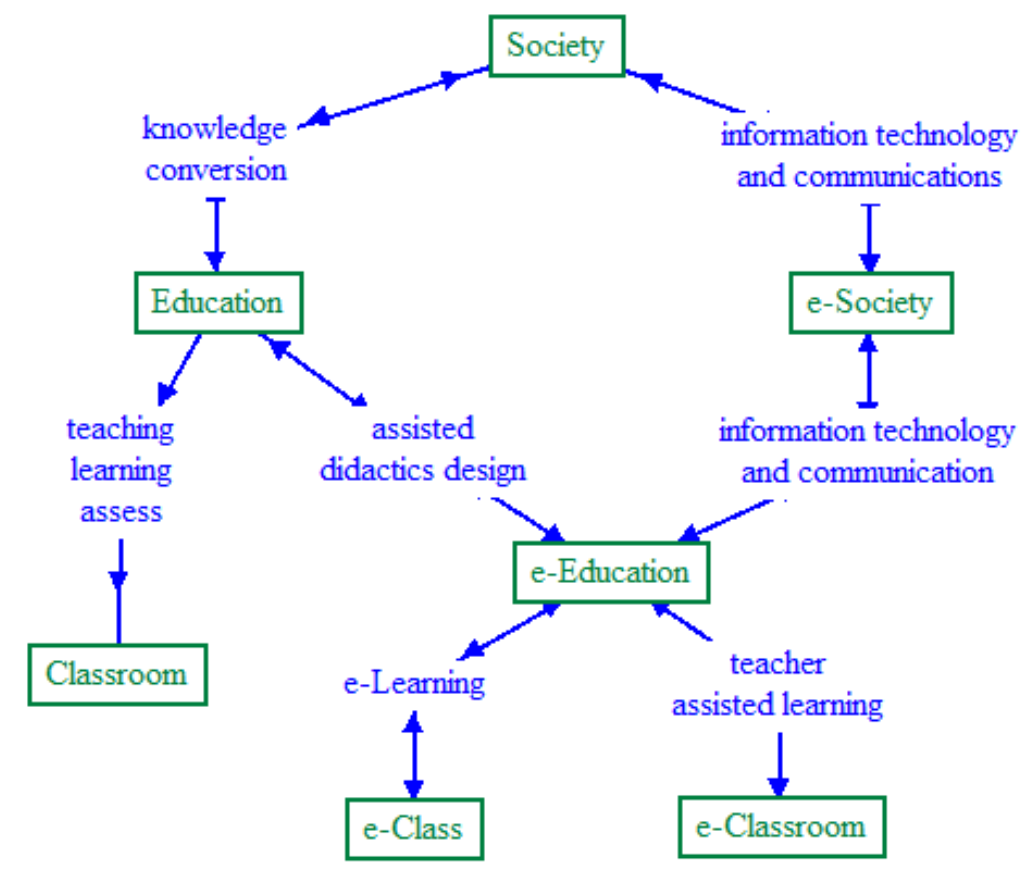

Fig. 3. Learning in e-Society: a terminological paradigm

In our approach, the e-science is defined as an application of the informatics technology in science, and the conceptual paradigm for learning in a scientific environment is presented in Fig. 4).

At this level of cognition proper terminologies are formed in a constructed version, concepts are defined, methodologies of research are elaborated and scientific equipment is introduced and they are developed as systems.

According to [16], the term "e-education" refers to the application of Internet technology to the delivery of learning experiences. E- education takes place in formal electronic classrooms, on corporate intranets used for just-in-time training, audio and video teleconferencing and in a variety of other technology mediated learning spaces. The primary tools of e-education are e-mail, emeetings, e-expeditions, and the methodologies of a pedagogy known as e-learning.

In the website Semiotics of Law (http://semioticsoflaw.com/site/home.php), in the section E-Education, it is mentioned that e-education is the definition for all types of electronically enhanced education, with emphasis on education, which is a stark contrast 
to e-learning. It would not be correct to perceive e-education only as a set of pedagogic practices with emphasis on learning with the use of electronic instruments. Education itself changes fundamentally where electronics are at stake; it will have a different character and a different understanding of the social relations that sustain the process of education. In [17], the authors consider that e-education is a broad term that generally refers to any kind of learning done with a computer and Internet connection or CD-ROM. At the same time, e-education is essentially the network-enabled transfer of skills and knowledge. E-education refers to using electronic applications and processes to learn. The central idea of the authors' paper is to present e-education as a new method for teaching, and to get to know the main aspects of it. They founded e-education very useful but with some problems to change the systems that work nowadays; the main problems appeared to be the old mentality and the lack of technology.

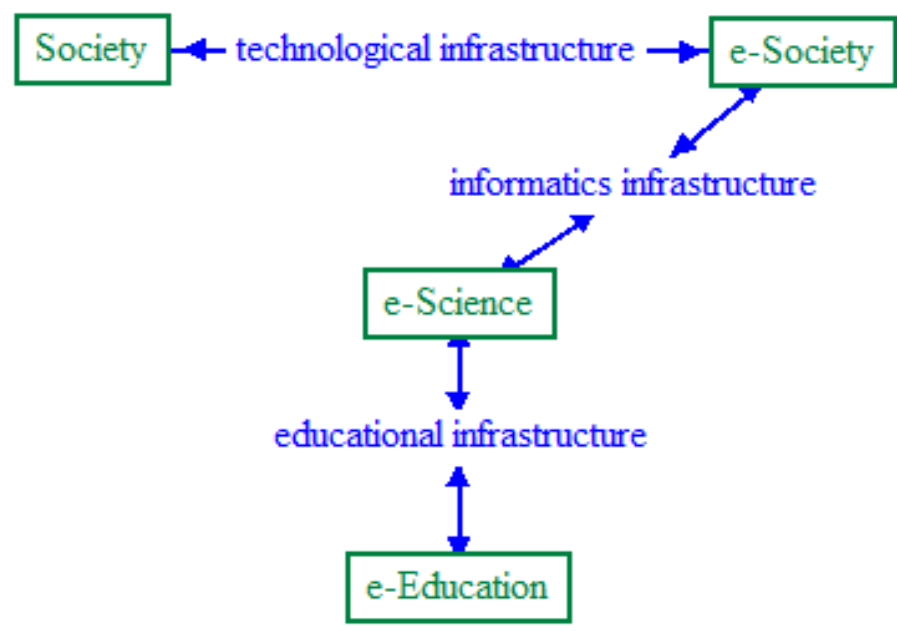

Fig. 4. Learning in e-Society: a conceptual paradigm

Related to previous research [12], which constructs an educational paradigm for our society, in this approach the e-education is defined as an application of assisted didactic design in education and e-learning is developed as an electronic support for e-class.

\section{Theoretical Framework}

Scientific research domain is responsible for creating new knowledge. In [18, pp.3-5] the author synthesizes that scientific research may be structured into two main groups: empirical, factual or descriptive sciences, and non-empirical, formal or theoretical sciences. The empirical sciences aim at exploring, describing, understanding or explaining, and predicting events. While statements in the empirical sciences must be controlled by facts from experience, which are empirical facts, within non-empirical sciences statement need not refer to empirical facts. In this context, [19] sustains that it is a condition of the intelligibility of experimental activity that in an experiment the experimenter is a causal agent of a sequence of events but not of the causal law which the sequence of events enables him to identify. So, the author concludes that there is an ontological distinction between scientific laws and patterns of events. The most important achievements within the science are twofold: first the inventions and discoveries, which imply innovations and an enhanced technological infrastructure, and then the development of new concepts which change human relations, because we understand the world using our concepts. Our concepts are organized into a cognitive infrastructure; they evolve as systems of concepts, and over time they are configured as theories based on personal experiences.

According with previous research, [11] defines the article as the basic result of a scientific research activity and proposes a working model developed as a paradigm in order to 
explain this context. Such an approach requests conceptual delimitations and redefined notions dedicated to merge the learning process in e-environment. The working model is refined in [20] where, it is concluded that the articles are designed as applications of the conceptual framework proposed by the author and they are finalized as generic study cases or analytical or theoretical frameworks. According to a concepts map approach, [12] details the generic study cases as practical or theoretical study cases. First situation reflects the paper focusing on the object language while the second one reveals the work concentrating on the meta-language in the scientific research. Refining the paradigm, as we presented in Fig. 1, an adapted working model proposed as a paradigm for scientific research articles is presented in Fig. 5.

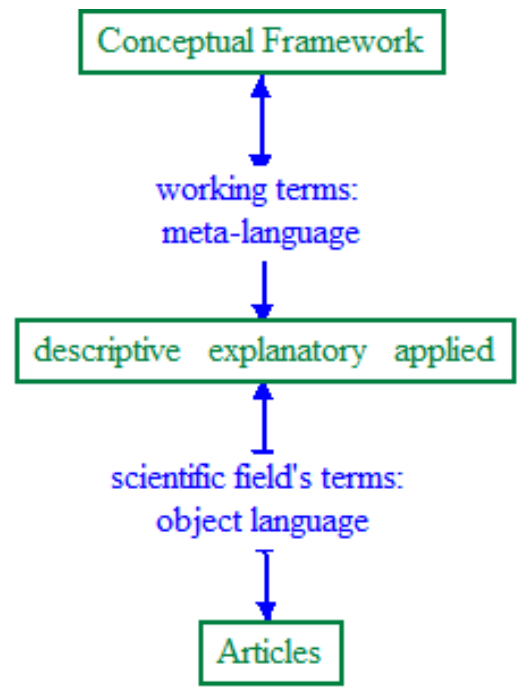

Fig. 5. The paradigm of the scientific research articles

Analyzing scientific research as a selfeducational activity, the article could be investigated as a learning object so for the owner, and for the community with the professional interests in the same field's area. Matching the interests of the other researchers or students depends on the adequate informational granularity of the learning object; in this context, the scientific field's terms could be reflected as a concepts map integrated in a pyramid of concepts enabled to know, understand and apply, while the working terms could be interpreted as a concepts map aggregated in a concepts network enabled to analyze, systematize and evaluate the scientific field's terms.

Using the previous paradigm, the e-society could be related as a working term, and the global information system can be analyzed as a scientific field's term, which it generates convergences: people converge into virtual communities, professional skills converge to create new professions, and concepts con- verge to form new concepts. As a continuum versioning process, technology supports converging in order to be created new technologies; this type of enabling was possible while a computer was included in a computer, and so it become tool, tutor, tutee, and in present, it could be conceptualized as a context of knowledge, with high granularity, as pattern. E-science requires reconsidering the relationship between theory and practice and the paradigm of space and time for learning. Escience transforms the articles in e-articles, and as a pattern applied, objects learning are developed, designed and implemented as eobjects learning.

The e-article is the result of a scientific research activity but, at the same time, it represents e-learning for academics. According to a report about research publication characteristics and their relative values published in [21], scholars consider many factors when judging the potential quality of articles and deciding which articles to read. Since readers 
cannot know the intrinsic value of an article before reading it, they must use other clues to judge its quality and to estimate what value it may have to them. The problem is that an increasing amount of information is being published electronically. In this way, we observe a balance between the competences of the researcher regarding selections for reading and the quality of his e-articles. It is important for this equilibrium the publishing organization's guideline and support.

For example, INDERSCIENCE Publishers highlights that metadata consisting of title, author details, abstract and keywords, is a vital part of any paper, since, in our online world, it is the metadata which is freely available to all users and which gets sent to many and varied online sources, from which users undertaking online searches will trace the paper (see http://www.inderscience.com/www/id31_key words.pdf).The guidelines of this publisher require for title to be "as short as possible, with no abbreviations or acronyms"; the abstract should count approximately 100 words, maximum 150; the keywords should contain approximately $10-15$ words or phrases. The keywords field should contain ALL the essential word/phrases in the title; similarly, the keywords field should contain ALL the essential word/phrases in the abstract; additional keywords from the full text can be added if the author(s) feel(s) they are relevant, but only if they add significantly to the likelihood of the paper being retrieved, i.e. if they are "key"; where applicable, the title of the journal should also appear in the keywords.

Exploring the INDERSCIENCE Publishers website, we find 54,141 articles organized in 368 journals. The user can browse the journals by titles or by subject. There are ten subjects: Computing and Mathematics, Economics and Finance, Education, Knowledge and Learning, Energy and Environment, Healthcare and Biosciences, Management and Business, Public Policy and Administration, Risk, Safety and Emergency Management, Science, Engineering and Technology, Society and Leisure. Each of them contains between two and ten categories. For exam- ple, Education, Knowledge and Learning contain three categories: Education and LifeLong Learning, Knowledge Studies and Learning and Human Resources Development. First category includes 12 journals, the second one ten journals and the third has a list with 12 journals. One of the journals in the first category is International Journal of Technology Enhanced Learning. This journal has an ISSN online: 1753-5263 and an ISSN print: 1753-5255, and contains six issues per year. Topics for this journal includes: an emerging episteme, the theories, the technologies, the practices and the applications in domain. The issue 2012 vol. 4 no. $5 / 6$ has seven articles. First of these, "Learning analytics: drivers, developments and challenges", written by Rebecca Ferguson, with DOI: 10.1504/IJTEL.2012.051816, presents an abstract with 107 words and 15 keywords including 30 words. The article is limited at 13 pages. This journal is indexed in Scopus (Elsevier), Academic OneFile (Gale), ACM Digital Library, Expanded Academic ASAP (Gale), Google Scholar, Inspec (Institution of Engineering and Technology) and Scirus (Elsevier). This Journal is listed in: Cabell's Directory of Publishing Opportunities and Excellence in Research for Australia (ERA): Journal list 2012.

Another example is Emerald Group Publishing Limited, which at the end of 2012 had 55 journals and three Book Series ranked by Thomson Reuters (ISI). Emerald has customers in over 130 countries and contributors in over 205 countries. Articles of this publisher located in the section Resources for authors contain: a submission check-list for the authors, dedicated forms, and specialized guides

(http://www.emeraldinsight.com/authors/wor kshops/ggp_online.htm); the submission check-list is consisting of: format, length, title (which does not exceed eight words), structured abstract, keywords (maximum eight), classification, headings, figures, tables, references (Harvard style), and permissions. In section How to Guide there are available examples of structured abstract for: literature review, case studies, conceptual 
paper, research paper, and general review. In order to offer an enhanced service to their librarian, author and researcher communities, Emerald had planned to migrate to Atypon's Literatum online publishing platform during July-August 2013.

[22, p. 37-40] highlights that keywords typically: a) allow readers to judge whether or not an article contains material relevant to their interests; b) provide readers with suitable terms to use in web-based searches to locate other materials on the same or similar topics; c) help indexers/editors group together related materials in, say, the end-of-year issues of a particular journal or a set of conference proceedings; d) allow editors/researchers to document changes in a subject discipline (over time), and f) link the specific issues of concern to issues at a higher level of abstraction. The same author lists several different ways of choosing keywords: authors supply them with no restrictions on the numbers allowed, authors supply up to a fixed number (e.g. six), authors supply key words as appropriate from a specified list, editors supplement/amend authors' key words, editors supply key words, editors supply key words from a specified list, referees supply key words from a specified list, keywords are allocated according to the 'house-rules' applied to all journals distributed by a specific publisher, and keywords are determined by computer program at proof stage.

In 2010 ELSEVIER (www.elsevier.com) began introducing article-based publishing for journals, making final and citable articles available online faster, and improving their find ability. Articles will be published as soon as possible without waiting for an issue to be compiled; they will appear in an "Issue in Progress". This approach assures that the final and citable articles are published without needing to wait until a journal issue is complete, and publication process reflects industry shift from print to electronic publishing. In 2011 ELSEVIER introduced prototypes that incorporated a newly developed article format, in seven scientific areas, each tailored to the needs of the relevant commu- nities. For psychology \& Cognitive Science, some article features are: diagonal reader, experimental flowcharts, stimuli examples, presentation, interactive graphs and map; for Business Management there are available research highlights, supplementary videos, data analysis, journal information, interactive tables; for Mathematics and Computer Science, article features are: LaTeX (MathJax) rendering, math quotes, formula display in the right sidebar, knowledge tree, corollaries, lemmas, theorems, remarks. The publishing process begin with matching the authors' abstract to a journal, where it is available a dedicated interactive service or it is possible individual searching based on title, date, editor or ISBN/ISSN. The author artwork instruction, version 1.2 available from July 2012, offers generic information about recommended file formats and images from other applications, and about submitting video content to be include within the body of an article or multimedia as supplementary data. Many Elsevier journals also require authors to choose a subject classification during the online submission process. This classification helps editors to select appropriate reviewers. After submitting the paper, the final step consists of checking the status. It is important to know that between 40 and $90 \%$ of all manuscripts submitted are rejected before or after external peer review; in some cases, the journal the author had chosen is simply not the right one, it is mentioned in Elsevier guideline Understanding the Publishing Process.

Every year, ELSEVIER accept and publish more than 250,000 journal articles. ELSEVIER community includes 7,000 journal editors, 70,000 editorial board members, 300,000 reviewers and 600,000 authors. There are 61 offices and five warehouses in 24 countries.

For academics, developing research skills includes finding information in the library, identifying and selecting relevant information, improving reading comprehension; these activities generate patterned notes which are finalized by recording and using information [23, pp. 111-127]. 


\section{Analytical Framework}

In an educational approach, our society could be analyzed in every stage of its development as a whole of tacit knowledge. Defining learning as the process of developing the cognitive infrastructure, Fig. 6 reflects the statements "lifelong learning" or "lifelong learners" as soon as knowledge is presented as an application of the cognitive infrastructure. The two statements depends on the cognitive infrastructure' nature, which can be a social or a virtual one. Since the application refers to an individual, the knowledge is stored as experience as an education function, otherwise there are developed cognitive infrastructure as e-objects knowledge usable in knowledge transfer. As soon as the knowledge transfer has an instructional pur- pose, the e-objects knowledge become eobjects learning, with different granulation and they are designed using didactics theories, categories, and principles. For elearning objects the design is a computer assisted one, while the e-objects learning could be used in an assisted instruction activity. The main difference between the two learning situations is that the second one is designed as a social based process. This approach is based on the conceptual framework for didactic design presented in [12], which was initially intended as a terminological paradigm, and which was updated as a conceptual paradigm of learning; in this case, the educational infrastructure could be analyzed as e-science for specific purposes.

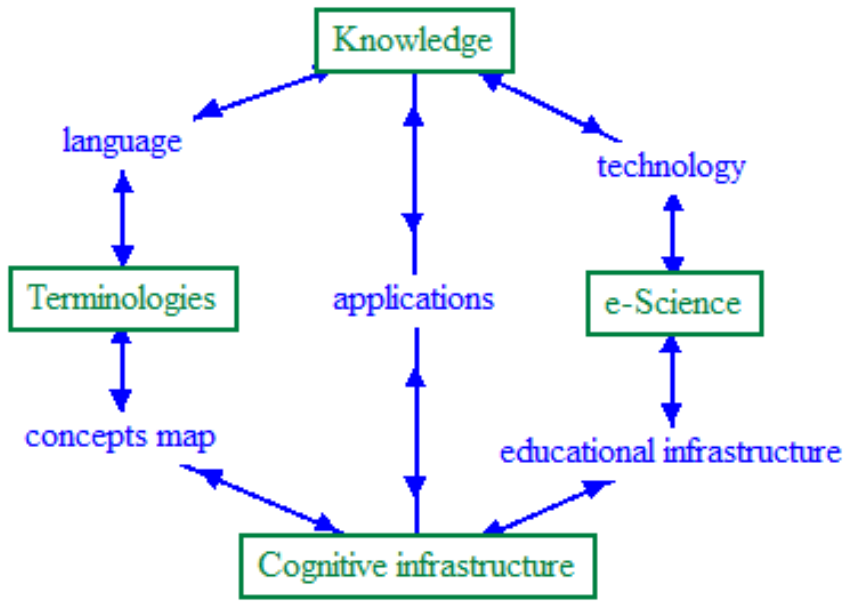

Fig. 6. The paradigm of Learning in a Scientific Environment

According to the statement that reality is complex and unlimited, [18] identifies three principal strategies to focus a scientific investigation: experimental, reductive and explicative. In an experiment the unit of analysis is an operation, which is carried out under controlled and restricted conditions. The scientist must be capable of manipulating, varying and measuring the relevant variables. Therefore, the experiment should preferably be conducted in a laboratory or in circumstances where the influence of external variables can be either eliminated or calculated. The aim of the reductive strategy is to use many units of analysis, but reduce the number of variables. This strategy makes it possible to formulate context-independent theo- ries about patterns and surface structure. The explicative strategy is practiced within the humanities and social sciences. This strategy is effective in order to understand complex phenomena in the context in which they occur. The aim of the explicative strategy is to focus our attention on one unit of analysis - a case-simultaneously accommodating as many relevant variables and qualities as possible. Thus the case may be understood as a complex whole. The same author considers that a strategy finally, links methodology to theory, defining the methodology as being a recommended set of methods for collecting and analyzing data. Such kind of vision assures for each researcher a conceptual infra- 
structure for developing knowledge in a particular scientific field.

The conceptual paradigm proposed in Fig. 6 explains the possibility of developing applications pattern-oriented, which integrates gradually informatics infrastructure. So, we can identify three types of dedicated applications designed for validation of the e-article, and, at the same time, we can identify two type of e-articles developed in a high granulation content environment oriented learning. Both classes have the same educational purpose: harmonizing learning in a scientific environment.

The first application of e-science as an educational infrastructure for e-articles is plagiarism detection service, which rates the papers for similarities to previously published work. A native application of e-science is the automatic system for determining the similarity of programs.

A second application is the taxonomy developed as hierarchical levels under each termfamily of a thesaurus of a scientific field's terms.

The third application could be designed as a lexical analysis based on Bloom taxonomy for the e-article's content evaluation. This type of investigation could highlight the level of complexity of the paper's research and could be correlated with the vocabulary shift. For example, many of the most common English verbs tend to be replaced by Latinate verbs having a more precise meaning. These three types of application correspond to the three types of paradigms described in the conceptual framework section of this paper: lexical, terminological and conceptual paradigms, developed on the methodological approach based on concepts map theory.

The first type of e-article which promotes the high granulation content environment oriented learning is the collaborative e-article, which is developed between the author and a supervisor collaborating as a mentor, while a second type, the interactive e-article is elaborated within a self-validation methodology.

One of the first component of e-science, developed as an educational infrastructure is the word processor, which offers to the au- thor a dedicated environment in order to create work papers, research reports or textbooks. There is a system of knowledge applications which refer to spelling and grammar, define a term or access to the thesaurus. The user can use the built-in screen reader, Narrator, to read and create documents. There is a mini translator which provide a quick translation when the user focuses the cursor on a word or on selected paragraphs. The author could obtain statistics in the current document; he could compare two versions of a document or he could combine revisions from multiple authors into a single document; the environment is a collaborative one, as soon as the supervisor could review the content. This system of knowledge applications defined the standard textbook structure which it means there are techniques to organize the content as an educational infrastructure.

The author could define headings as the base of organizing the content in a hierarchy of knowledge, which finally assure the table of contents generation.

The knowledge representations as illustrations, included in document as pictures, shapes, smart art, charts or even screenshots, have to be labeled, then referred using a cross-reference option, and finally a list of figures could be generated, as a qualitative method for knowledge conversion.

Creating, labeling, referring series of data edited in tables, finally are synthesized in a list of tables as a quantitative research method included in the textbook.

Numbered or bulleted lists are also knowledge objects which can be referred in a cross-reference system in order to highlight structured information.

One of the most important technique, developed to presents the author's intention regarding the keywords of the studied field is the index which can be generated after marking the entries for a specific terms. The reader can find quickly explanations for them and how they are distributed through the chapters.

For an author, the first objective consists of originality, regarding the work reflected in 
the document. For this, there are options for managing the sources, applying the styles (12 standards are built-in), generating the bibliography, and insert citations as placeholders. Two annexes are recommended to be elaborated manually: the list of acronyms and the glossary. The first one is more than necessary in some field where they abound in. This list will be sorted and explained in the same way they appear first in the text. The second one, is an alphabetical list of the working terms, completed with the source of the explanations.

\section{Case Study}

The paradigms proposed and analyzed in this article as arguments in reconsidering the relationship between theory and practice for learning activities in public education could be confirmed by the technology timeline and its applications in different domains. In this way, it's remarkable the idea published 26 years ago in a chapter Instructional Software in [24, pp. 103]: "Over the past few years the quality of computer-based instructional software has undergone considerable improvement. Many of the early programs were written by computer buffs who had little background in learning theory or pedagogy. As educators became familiar with programming techniques they began to create lessons that met their instructional needs but were far from being technically elegant. Today, how- ever, an effort is being made to unify the two camps and thereby create sound lessons that are also technically well programmed".

The case study of this approach is founded on the analytical framework for the paradigm of learning in a scientific environment described in section 4, where the application is designed as an educational infrastructure. In this case, the personal computer, created as an informatics technology (tool), is developed as an educational technology (tutor) and then it is transformed as an environment for designing pedagogical situations enabled to support refining learning (tutee). This type of educational infrastructure assures competencies for the content, interaction as a support, and class work in the context of a discipline, these features representing the main characteristics of a standard application in assisted instruction.

In order to respect a transitional solution for mind challenge, the case study propose an exercise adapted from [25, pp.163]: The statement of this exercise is: Edit in the second square the correct Roman numeral, referring to the image presented in Fig. 7.

So as to solve this exercise, we use an electronic sheet and, it is important to mention that, in this case, the interactive application involves two steps: first we built the statement and then we solve it.
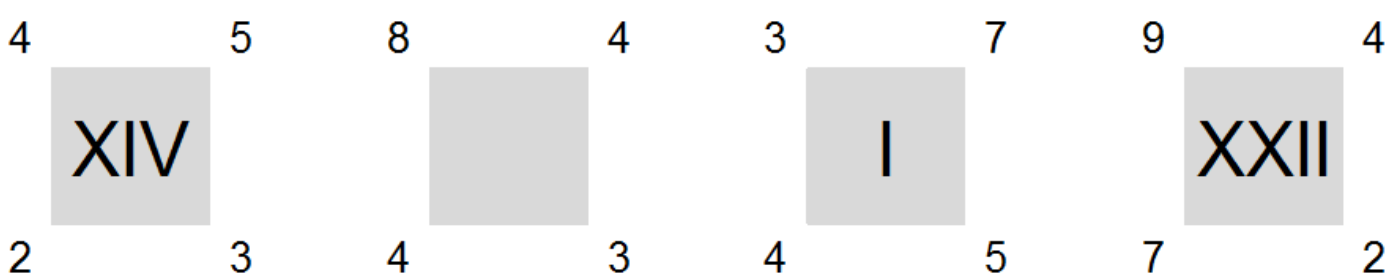

Fig. 7. Fill the square with the correct Roman numeral

The application, in the initial stage, has an interface consisting of six levels of interaction, which is presented in the image which can be viewed in Fig. 8. The six ranges of the applications are: (1) the title and references area, (2) the solution (the steps to follow in order to solve; from this point of view, the application is considered a tool), (3)the Tutor(where each step is completed with instructions), (4) the tu- tee (the button Check assists the learner, confirming the right actions, and the button RESET reconfigures the environment, if it is necessary or if the learner wish this action or if the user click this button involuntary), (5) the assistance for working area, where the user could command or he could learn how to obtain a specific configuration, and (6)the level designed for checking Understanding. 


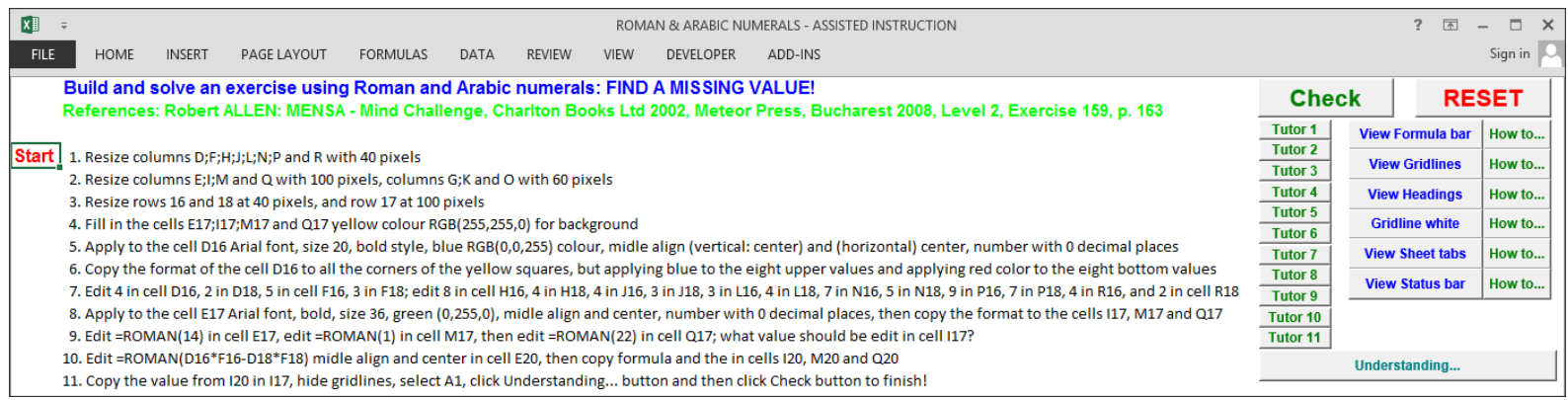

Fig. 8. The application's interface in the first stage

All the options existing in the application are contextual command buttons, so each of them offers information as it is needed; so the buttons regarding working area have contextual labels (View/Hide) and the explications for the buttons How to... offer also contextual help.

The actions recommended for the learner are: first, reading a step, viewing the help offered the corresponding tutor button, applying the instructions and then checking how he applied. In the left area of each step could be seen a confirmation (OK) if the action was passed, otherwise it will be displayed the number of the requirements to solve (Req:n).

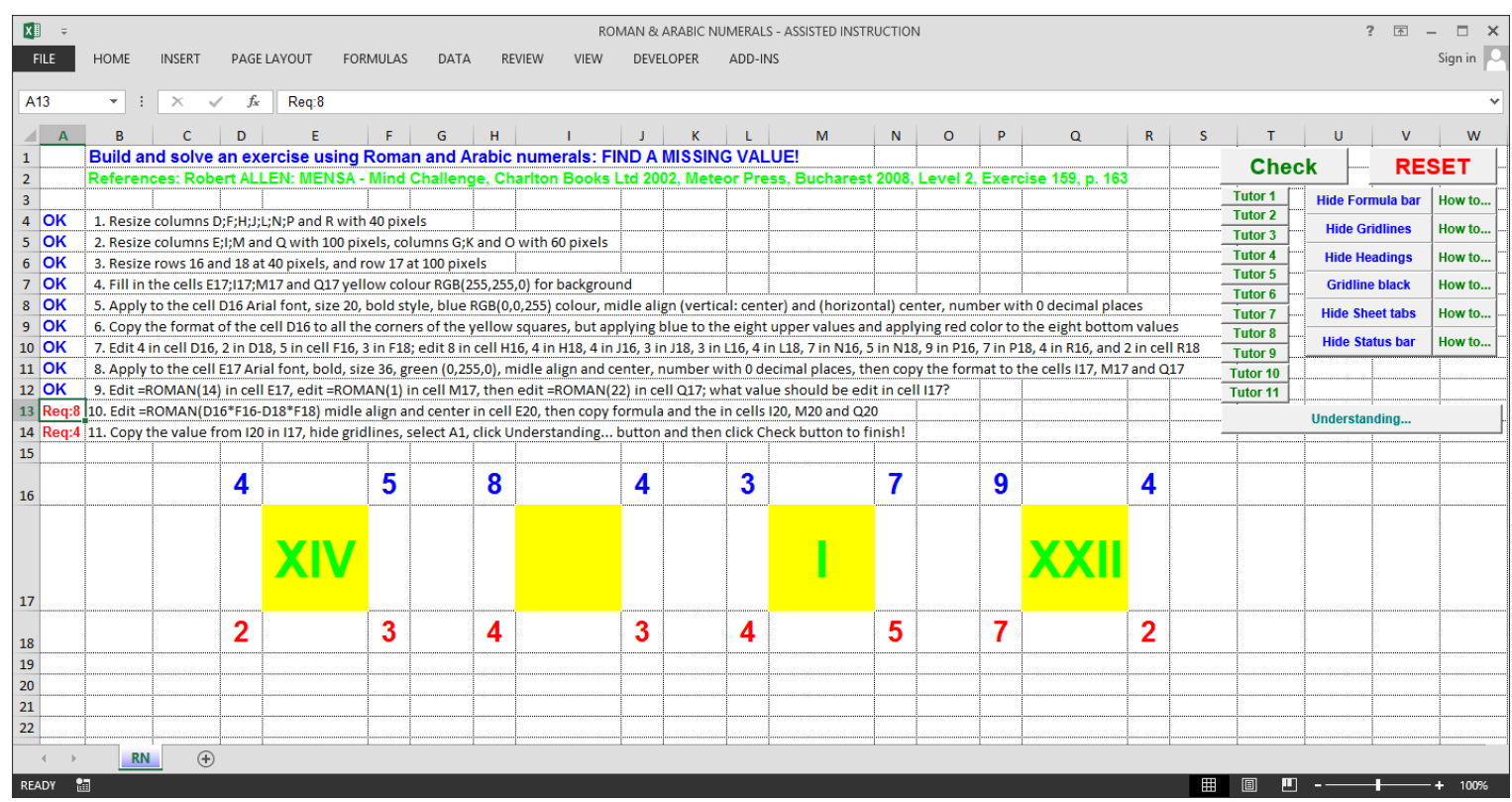

Fig. 9. The application's interface for working in progress

In the image presented in Fig. 9 it could be seen the statement of the initial exercise, already built by the learner during the first nine steps, which can be now understood using the Roman function and chromatic support of the application. A supplemented information is revealed when the learner click the button Understanding... and he read about the class of the exercise as a basis concept of the knowledge structures.

\section{Conclusions}

As an educational infrastructure, in a cognitive approach, classical use of personal computers was dedicated to solve traditional problems with the new technology. The best examples are the type-writer and the desktop metaphors. This model is a reflection of the lexical paradigm of learning. Next generation of the problems solved by computer assisted 
instruction reflected the terminological paradigm of learning, where solutions were produced individual, as soon as the computer was an extension of the individual cognitive infrastructure. Representative examples are when solving the various kinds of traditional intelligence tests using the adequate software as environment, as they are presented in [12], [26] and [27]. The new challenges are validating the scientific researches activities, using an educational infrastructure e-science based, which assures learning defined as sequential knowledge, understand and apply actions and self-validation of the results of this process. This third model is a representation of the conceptual paradigm of learning based on assisted instruction situations. This type of applications corresponding to the third paradigm has a twofold objectives: converting knowledge in order to integrate it in the cognitive infrastructure and learning the new environment.

\section{References}

[1] L. Zynda, Introduction to the Philosophy of Science, lecture notes from PHI 204, Princeton University, 1994, http://www.soc.iastate.edu/sapp/soc401ku hn.html

[2] A. Bird, The Structure of Scientific Revolutions and its Significance: An Essay Review of the Fiftieth Anniversary Edition, The British Journal for the Philosophy of Science, http://bjps.oxfordjournals.org, 2012, vol. 63 (4): 859-883, doi: 10.1093/bjps/axs031,

http://bjps.oxfordjournals.org/content/63/ 4/859.full

[3] M. R. Forster, Hard Problems in the Philosophy of Science: Idealization and Commensurability, in R NOLA and $\mathrm{H}$ SANKEY (Eds.) After Popper, Kuhn \&Feyerabend: Issues in Theories of Scientific Method,Australasian Studies in History and Philosophy of Science, Kluwer 2000

[4] J. Grix, The Foundations of Research, Palgrave MacMillan, New York 2004, pp. 7-11, 36-39
[5] S. Grinev, Terminological Foundations of Reasoning: Towards the General Theory of Evolution of Human Knowledge, Journal of the International Institute for Terminology, Vol. 14, 2003, TermNet Publisher, pp. 41-51

[6] R. Garcia, R. Calantone, A Critical Look at Technological Innovation Typology and Innovativeness terminology: a literature review, The Journal of Product Innovation Management 19 (2002) 110-132

[7] L. Blaxter, C. Hughes, M. Tight, How to research, Open University Press, Maidenhead, Philadelphia 2003, 286p.

[8] P. Pistorio, Towards The e-Society, Future Horizons, European Electronics 2000, Tenth Annual International Electronics Forum, Naples, October $9^{\text {th }}, 2000$

[9] Z. Khabaziyan, H. Teimori, M Hekmatpanah, Planning E-Citizen: A Step toward E-Society, World Academy of Science, Engineering and Technology 592011

[10] Y. Zheng, G. Walsham, Inequality of what? Social exclusion in the e-society as capability deprivation, Information Technology \& PeopleVol. 21 No. 3, 2008pp. 222-243, Emerald Group Publishing Limited, DOI 10.1108/09593840810896000

[11] G. Zamfir, Quality-Quantity Paradigm in Assisted Instruction, Journal of Applied Quantitative Methods, vol. 5, No. 4, Winter 2010, http://www.jaqm.ro

[12] G. Zamfir ,Concepts Map Approach in e-Classroom, Informatica Economică, vol. 16, No. 3/2012, pp. 124-135

[13] M. D. Bocoș, Instruirea interactivă, Repere axiologice și metodologice, Editura POLIROM, Iași 2013, 470 p.

[14] B. Wilk, Installation of complex $e$ Science applications on heterogeneous cloud infrastructures, Master of Science Thesisin Computer Science, Krakow, August 2012, http://dice.cyfronet.pl/publications/source /MSc_theses/bw_msc_thesis.pdf

[15] T. Hey, S. Tansley, and K. Tolle (Editors), The Fourth Paradigm, DataIntensive Scientific Discovery, Microsoft Research, Redmond, 2009, http://research.microsoft.com/en- 
us/collaboration/fourthparadigm/4th_para digm_book_complete_lr.pdf

[16] G. T. Grimes and C. Whitmyer, EEducation: What is it? The University of the Future, Published by FutureU Press, San Francisco 2009, http://futureu.com/shared_resources/eeducation_what_is_it.pdf

[17] P. Narula, P. Narula, S. Kaur, EEDUCATION, International Journal of Computing \& Business Research, ISSN (Online): 2229-6166, Proceedings of 'ISociety 2012' at GKU, Talwandi Sabo Bathinda (Punjab), http://www.researchmanuscripts.com/ind ex.php?option=com_content $\&$ view $=$ articl e\&id=67\&Itemid $=76$, http://www.researchmanuscripts.com/isoc iety2012/10.pdf

[18] R. Johansson, Theory of Science, Royal Institute of Technology, Department of Infrastructure, Urban Studies / Built Environment Analysis, Stockholm, September 2004 http://www.infra.kth.se/bba/bbasvenska/l ager2/1U1030\%20LectureNotes.pdf

[19] R. Bhaskar, A Realist Theory of Science, ROUTLEDGE Taylor \& Francis Group, London and New 2008, http://lc.zju.edu.cn/STS/TuShu/upfiles/4e 28481f-46a7-420c-a6d2c5bcd96eb33d.pdf

[20] G. Zamfir, Theoretical and Factual Meaning in Assisted Instruction, Infor- matica Economică, Vol. 15 No. 2/2011, pp. $94-106$,

[21] C. Tenopir, S. Allard, B. Bates, K. J. Levine, D. W. King, B. Birch, R. Mays, and C. Caldwell, Research Publication Characteristics and Their Relative Values: A Report for the Publishing Research Consortium September 2010, University of Tennessee, School of Information Sciences Publications and Other Works, http://trace.tennessee.edu/utk_infosciepub $\mathrm{s} / 20$

[22] J. Hartley, Academic Writing and Publishing, A practical handbook, Routledge, London and New York, 2008, Master ebook ISBN: 0-203-92798-2, 208 p.4

[23] S. Cottrell, The Study Skills Handbook, Palgrave Macmillan Ltd., New York 2008

[24] R. V. Bullough, L. F. Beaty, Classroom Applications of Microcomputers, Merrill Publishing Company Ohio 1987, 342 p.

[25] R. Allen, MENSA - Mind Challenge, Carlton Books Ltd 2002, Meteor Press Bucharest 2008, 304 p.

[26] G. Zamfir, Didactics in Assisted Instruction, Human-Computer Interaction National Conference, ROCHI 2010, pp. 5964

[27] G. Zamfir, Learning e-Learning, Informatica Economică, vol. XIII, No. 4/2009, pp. 51-62

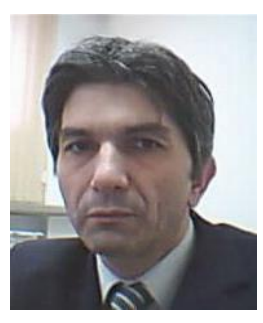

Gabriel ZAMFIR has graduated the Faculty of Planning and Economic Cybernetics in 1984 when he was distributed as analyst in the Research Institute for Computer Technique. In 1993, he joined the staff of the Bucharest University of Economics. In 2000, he finalized the doctoral thesis Computer Assisted Instruction in Economics. Currently he is full Professor of Computer Assisted Instruction within the Department for Training the Teachers, involved in designing education for metacognitive disciplines. 